\title{
Strategies for Energy Efficiency Improvement in Zimbabwean Industries Using the Energy Audit
}

\author{
Wilson Mungwena ${ }^{1}$, Cosmas Rashama ${ }^{2}$ \\ ${ }^{1}$ Department of Mechanical Engineering, University of Zimbabwe, Harare, Zimbabwe \\ ${ }^{2}$ Department of Electrical Engineering, University of Zimbabwe, Harare, Zimbabwe \\ Email:wmungwena@gmail.com
}

Received March 20, 2013; revised April 22, 2013; accepted April 29, 2013

Copyright (c) 2013 Wilson Mungwena, Cosmas Rashama. This is an open access article distributed under the Creative Commons Attribution License, which permits unrestricted use, distribution, and reproduction in any medium, provided the original work is properly cited.

\begin{abstract}
Energy efficiency is a modern approach for using energy resources economically. Energy audit ensures that every unit of energy gives the maximum in terms of production. This paper brings out the advantages of using energy audit to save future installation of power generation capacity and load reduction of distribution systems. It also envisages the introduction of energy conservation techniques to eliminate sub-standard equipment.
\end{abstract}

Keywords: Energy Efficiency; Energy Audit; Energy Conservation

\section{Introduction}

As civilization grows, human beings consume more energy. Table 1 gives the chronological growth of energy consumption by man [1].

The above detrimental effects can be mitigated by sustainable development. The objectives of sustainable development are: as man consumes more energy, the economic growth has caused rapid depletion of key natural resources like fossil fuels, forest, fresh water and air quality. There is also the possibility that large scale deaths from pollution related diseases may occur, because basic life-support systems of the planet are affected.

The Zimbabwean energy scenario is currently in a precarious state with available capacity almost $50 \%$ of national requirements. This is because there has been no new generation assets installed for the past thirty or so years. The critical shortage of energy has affected all sectors of the country with industry operations at $40 \%$ partly because of shortage of electricity and obsolete equipment.

- Abundant resources maybe a substitute for depleted natural resources, e.g., solar energy for oil.

- Economic growth leads to capital accumulation which can be used as a substitute for natural resources such as energy conservation requiring capital investment.

- Continuation of technical augmentation, like more efficient power systems, more efficient consumption

\section{systems}

Table 2 summarizes resource options available for electric utilities [2].

Energy consumed in the plant is determined by whether we make or buy material. Materials used in industry have already an energy input built into it. It is required to estimate the energy content in products so that less energy intensive materials could be promoted to develop more energy effective products.

In industry, the reasons for high energy consumption though not exhaustive may be listed as:

- Inadequate modernization of plant.

- Continued use of obsolete technology.

- High specific energy consumption.

- Less efficient lighting systems.

Table 3 lists typical values of energies consumed in the manufacturing processes of materials in Zimbabwean industries [2].

Table 1. Energy consumption by man.

\begin{tabular}{|c|c|c|}
\hline People & Time & Energy consumption per day \\
\hline Primitive man & Before $1000 \mathrm{AD}$ & 4000 kilo calories \\
\hline $\begin{array}{l}\text { Man in agricultural } \\
\text { community }\end{array}$ & Around $1000 \mathrm{AD}$ & 10,000 kilo calories \\
\hline $\begin{array}{l}\text { Man in industrial } \\
\text { society }\end{array}$ & Around $1870 \mathrm{AD}$ & 60,000 kilo calories \\
\hline Modern man & 20th century & 350,000 kilo calories \\
\hline
\end{tabular}


Table 2. Resource options for utilities.

\begin{tabular}{|c|c|c|c|}
\hline Supply side & & Demand side & \\
\hline Option & Example & Option & Example \\
\hline 1. Conventional capacity & $\begin{array}{l}\text { Gas turbine, combined cycle, hydro, } \\
\text { pumped storage or upgrading of } \\
\text { existing plants }\end{array}$ & 1. Utility controls the load as needed & $\begin{array}{l}\text { Interruptible consumer load, appliance } \\
\text { control. }\end{array}$ \\
\hline $\begin{array}{l}\text { 2. Advanced technology } \\
\text { (high efficiency) }\end{array}$ & $\begin{array}{l}\text { Fluidised bed combustion of coal, } \\
\text { integrated gassifier combined cycle, } \\
\text { mini-hydro photovoltaics etc }\end{array}$ & $\begin{array}{l}\text { 2. Consumer installations encouraged } \\
\text { through utility incentives, } \\
\text { captive generation }\end{array}$ & $\begin{array}{l}\text { Captive generation must be mandatory } \\
\text { for power intensive industries like } \\
\text { cement, steel, aluminum, paper etc }\end{array}$ \\
\hline \multirow[t]{2}{*}{$\begin{array}{l}\text { 3. Co-generation } \\
\text { (high efficiency) }\end{array}$} & $\begin{array}{l}\text { Gas fired combustion combined } \\
\text { cycle, fluidized bed diesel combined } \\
\text { cycle }\end{array}$ & 1. New technologies & $\begin{array}{l}\text { Computers, robotics, microwaves, } \\
\text { magnets }\end{array}$ \\
\hline & & 2. Elimination of energy theft & $\begin{array}{l}\text { Effective metering and checking, } \\
\text { vigilance on consumer connections }\end{array}$ \\
\hline
\end{tabular}

Table 3. Energy contents of materials.

\begin{tabular}{lcc}
\hline \multicolumn{1}{c}{ Materials } & $\begin{array}{c}\text { Energy Consumed } \\
(\mathbf{M j} / \mathbf{K g})\end{array}$ & $\begin{array}{c}\text { \% of Cost of Product } \\
\text { Attributable to Energy }\end{array}$ \\
\hline \multicolumn{1}{c}{ Metals } & $20-50$ & 30 \\
1. Steels & $60-270$ & 40 \\
2. Aluminum alloys & $25-30$ & 5 \\
3. Copper & $80-100$ & 10 \\
4. Magnesium & & \\
\multicolumn{1}{c}{ Other products } & $30-50$ & 30 \\
1. Glass & 10 & 4 \\
2. Plastic & 25 & 30 \\
3. Paper & 12 & 20 \\
4. Inorganic chemicals \\
(average values)
\end{tabular}

Nowadays, a total review of weight/strength needs is undertaken by the automobile and aircraft industries using the Finite Element Analysis. As a result, more of plastic and aluminum is used in the industry. This gives better HP/weight ratio in the product and process of manufacture as well as in the lifecycle energy costs of the product.

Recycling of materials is energy economical. For example, recycling of old/broken glass pieces requires $1 / 4$ the energy required for manufacturing new glass; recycling of iron scrap requires $1 / 4$ the energy required to manufacture new iron metal; recycling of aluminum scrap requires $1 / 2$ the energy required to manufacture new aluminum and recycling of used paper requires about $1 / 2$ the energy required for new paper manufacture.

\section{The Energy Audit}

The energy audit is a survey done on an organization to ascertain the energy consumption and to examine energy conservation options. The typical objectives are:

- To review energy consumption patterns so as to evolve industry-wise norms and database.

- To classify consumers with respect to load demand who $75 \%$ of total large supply industrial consumption.

- To make energy audit mandatory once a year with HT consumers with maximum demand greater than 500 KVA.

The activities of the energy audit are: [3]

- Electrical energy consumption month-wise vis-à-vis the finished product.

- Power bill study for each month focusing on KWh, KVA, power factor and production throughput.

- Analysis of the load curve to curtail/shift some loads to off-peak periods.

- Monitoring energy consumption of various equipment separately to check efficiency, harmonics starting currents power factor and taking remedial measures to achieve higher efficiency.

\section{American Case Study [4]}

Evidence of the importance of monitoring the consumption of various equipment separately to check efficiency was observed at Pacific Gas and Electric Company (PG\&E) that understood that businesses may need help with understanding their consumption patterns, and created the Pacific Energy Center (PEC) in San Francisco in 1991 to provide such assistance. The company initiated the Tool Lending Library as a service to customers to help customers understand and document their consumption patterns. Lending Library contained an array of measurement tools that were loaned out to California utility customers free of charge for load studies up to 30 
days or more in length. In order to prove the importance of a detailed breakdown of energy audit consumption data, PG\&E used its library equipment to measure the specific energy usage at the Pacific Energy Center building itself.

PEC staff monitored individual loads, and logged power levels, and cross-checked the results against overall energy usage to verify that the building's energy usage was indeed accounted for in the recordings. Once that was done, PEC staff compared the loads of the building to the common loads for other buildings of similar size and type, looking for consumption patterns that needed to be corrected. The energy audit found higher than expected baseline energy usage over the weekend. Analysis revealed that the high consumption was as a result of the amount of safety illumination during unoccupied hours, and the amount of refrigeration needed in their commercial kitchen. To address this issue, they reduced the wattage for safety illumination on weekends, and identified more efficient refrigeration equipment that would replace existing equipment when it reached the end of its useful life. They also found a boiler and an exhaust fan that were unnecessarily running constantly during the monitoring period.

Further, in 2011, the PG \& E Tool Lending Library completed over 1250 test equipment loans to customers. Borrowers estimated that the monitoring projects supported by these loans helped reduce energy demand by 157 megawatts and saved 92.5 million $\mathrm{kWh}$ of electrical energy in the year 2011.

\section{Achieving Energy Efficiency}

\subsection{Demand-Side Management}

Here, the utilities seek to directly influence demand for electricity in predetermined ways. The programs are load management, strategic conservation, demand reduction and development of captive power with cogeneration. The main objective of demand-side management is to influence the consumption patterns and behavior of consumers towards efficient use of electrical energy. This is achieved in the following strategic steps.

\subsubsection{Load Management}

Under this strategy, we direct load control in which portions of the load are under the direct operational control of the utility with the agreement of the consumers; indirect load control where the consumers may control their loads voluntarily \& alter the use of electricity in response to price signals and lastly power utilities implement tariffs with inbuilt mechanism to discourage wasteful energy consumption.

\subsubsection{Time-of-Day Pricing}

Under this strategy, the price elasticity of demand for electrical energy is assessed. This is quantified using an economic model for the electricity demand and then linear regression techniques are applied to estimate the price elasticity of demand. The tariff could indicate to the consumers when electricity is cheap/expensive. The aim is to produce tariffs which meet the utilities' financial targets. The price and demand can be coupled by the elasticity factor to achieve load shifting away from the peak time-of-day for different categories of consumers

Common forms of energy rate tariffs are given below:

a) Consumption limited tariff-consumer is only allowed to consume electricity to a limited extent.

b) Flat rate tariff-consumer is charged at a flat rate/unit no matter how much electricity they consume.

c) Block rate regressive/progressive tariff-cost/unit can decrease or increase per block of consumption.

d) Time-of day tariff-cost/unit depends on time of day or month of the year.

e) Bulk-rate tariff-special tariffs for large consumers.

\subsubsection{Demand Reduction}

The leveling of demands will decrease the maximum current flow. As loses vary with the square of the current, the lower current will result in reduction of the total energy requirements of the consumer and reduction of loses. Microprocessor base 'demand controllers' could be used to supervise the operations of the consumers' equipment. The first step is to obtain the consumers' demand profile. If the profile shows a few sharp peaks, then the equipment causing these peaks is identified and remedial measures are taken. In this connection, the consumers' major loads are classified into 4 categories like,

- Those which can be rescheduled.

- Those which can be deferred.

- Those which can be curtailed or eliminated.

- Those which are essential base loads.

Demand controllers increase the effectiveness by removing all the non-essential loads in addition to keeping the demand under a preset level. The control function can be by many types of systems namely,

- Instantaneous - controls all loads at any time during an interval if the rate of usage exceeds a preset value.

- Ideal rate-controls load when they exceed the set rate but allow a higher usage at the beginning of the interval.

- Converging rate-has a broad control bandwidth in the beginning of the interval, but tightens control at the end of the interval.

- Predictive rate- the controller is programmed to predict the usage at the end of the interval by the usage pattern along the interval and switches load to achieve the preset demand level.

Continuous interval-the controller looks into the past usage over a period equal to (or less than) the demand 
interval. Loads are switched in such a manner that no time period of an interval's duration will see an accumulation of KWh that exceeds the preset value.

Before any of the above controllers can be installed, a load survey should be made. This survey is an equipment/process audit. Each process and piece of equipment should be surveyed to find which loads can be switched off and to what extent they can be switched. Any loss of equipment life or mechanical problems associated with switching each load should be evaluated.

The simple fact is that no energy is used when equipment is shut off. Hence it is required to make sure that unused, redundant and idling equipment is shut off.

\subsubsection{Cogeneration [5]}

This is an important energy conservation strategy. Energy savings from cogeneration do not necessarily imply economic savings. Cogeneration will be an economical investment for a firm if the value of the electricity produced is greater than the incremental capital and operating costs incurred by the firm. Packaged cogeneration plants have potential applications in hospitals, hotels and industries. Cogeneration systems can be classified into two into 2 categories namely, topping systems and bottoming systems.

In topping systems, electricity is produced first in a turbine and some of the energy is exhausted and used in industrial processes.

In bottoming system, high temperature energy is produced first for applications like steel reheating process, cement kilns or aluminum furnaces; further heat is then extracted from the hot exhaust waste steam and transferred to a working fluid. The fluid is vaporized and used to drive a steam turbine to produce electrical energy. The figure below shows the fuel effectiveness.

a) Modern coal fired system

Maximum efficiency $=35 \%$;

Losses in condenser $=48 \%$;

Boiler losses $=15 \%$;

Other losses $=2 \%$.

b) Gas turbine cogeneration systems

Maximum efficiency $=90 \%$;

Exhaust losses $=10 \%$.

c) Steam turbine cogeneration system

Maximum efficiency $=84 \%$;

Boiler associated losses $=15 \%$;

Other losses $=1 \%$.

\subsection{Efficient Energy Use in Lighting}

Lighting constitutes an appreciable load and consists of an inefficient system of lamps and luminaries. Use of energy effective products will lead to the ultimate possibility of halving this connected load, thereby avoiding waste in a cost effective manner. The energy saving measures could be:

- Compact fluorescent lamps as replacement for GLS light points in hotels, commercial, domestic and other applications where $20 \mathrm{~W} / 40 \mathrm{~W}$ tube lights are too large.

- Electronic ballasts for fluorescent tube circuits as replacement in existing tubes and for incorporation in new lighting points. Theses operate at low voltages \& have instant start with easy installation, high power factor and immediate saving in connected load.

- Upgrading of fluorescent tubes to high pressure sodium lamps as recommended for techno-commercial considerations. Intelligent lighting as a practice can be followed in terms of the following steps.

- In many security situations, lighting is simply left on throughout the high risk period which is generally at night. Passive infrared protection systems are available which automatically sense occupancy and switch on light to specific zones providing round the clock security lighting with a huge potential for energy saving. The infrascan device includes passive infrared sensors, photoelectric sensors and timers. The integration of all these control elements provides an intelligent solution which is capable of dealing with potential security risks as well as continually adjusting to daylight levels.

- Energy saving, fully automatic controllers are available. These are designed to be installed in place of existing wall switches and fir into standard wall boxes. Electricity is wasted when people neglect to switchoff when rooms are vacated or when daylight makes artificial lighting unnecessary. The controllers respond only to physical occupancy within the confines of the room or area controlled by the individual unit. Automatic switching is activated by means of a double-dual-passive-infrared sensor system giving a $180^{\circ}$ beam coverage over a $170 \mathrm{~m}^{2}$ area. The controllers are fully programmable with internal switches allowing adjustment at the time of installation to suit individual situations. The time delay between a room becoming unoccupied and the lights being switched off can be set to either 1, 4, or 16 minutes. Occupancy in where full daylight does not penetrate can be considered by setting the ambient-daylight-sensitivity function off.

\subsection{Efficient Energy Use in Motors [6]}

\subsubsection{Efficiency}

Motors are fairly efficient at rated loads. In general threephase motors are more efficient than single-phase motors and larger motors are more efficient than the smaller ones. Motor voltage unbalance will increase motor losses due to the negative sequence voltage that the causes a 
rotating magnetic field in the opposite direction of the motor rotation. A $2 \%$ voltage unbalance will increase losses by $8 \%$; a $3 \%$ unbalance will increase losses by $25 \%$ and a $5 \%$ unbalance will increase losses by $50 \%$.

The power factor of three-phase motors is between $80 \%$ \& $90 \%$ at full load \& decreases as load is reduced. The installation of capacitors for power factor correction up to 0.95 or so) will decrease current requirements, thereby reducing $\mathrm{I}^{2} \mathrm{R}$ losses in supply lines.

\subsubsection{Oversized Motors}

If a motor is operated at a reduced load; then its efficiency begins to fall, it has higher starting current, lower running power factor and higher capital costs. Oversized motors lead to energy wastage.

\subsubsection{Soft Starters for Induction Motors}

These regulate the voltage at the motor terminals so that the magnetizing forces just meet the load demand. This boosts the efficiency of the motors operating below their rated outputs. Energy savings are significant for motors operating at less than $50 \%$ load for about $50 \%$ of the time.

\subsubsection{Efficient Motors Design}

These motors consume $5 \%$ to $8 \%$ less electricity than standard motors but more material is used to reduce copper and iron losses. These motors have a higher efficiency because higher grade steel is used and have special low friction bearings, added copper windings, close tolerances \& small air-gaps. They have a longer life because they run cooler than less efficient motors.

\subsubsection{Delta to Star Connection}

The winding of any under-loaded three-phase motor can be reconnected in star. This reduces the voltage across each winding to give $58 \%$ of its rated values. Motors constantly running at less $58 \%$ of full load will benefit.

\subsubsection{Variable Speed Drives}

They adjust the speed of the motor replacing constant speed motors. The variable-speed motors are energy effi- cient at reduced loads and reduced speeds to meet different load requirements. These drives are well established over a complete power range in all areas of Industry like basic industries, material handling plants, transport systems and utility companies for mechanical equipment such as machine tools, extruders, pumps fans compressors railways, elevators and conveyors.

\section{Conclusion}

Energy efficiency as a resource for saving future installation of power generation capacity \& unloading of distribution systems is a modern approach for using resources efficiently, especially in Zimbabwe where there are an acute power shortage and no investment in new generating assets. The energy audit aides this process by identifying the deficiencies in the existing systems. Energy conservation management, load management, time-of day metering, electricity pricing \& cogeneration efficient technologies are the various methods to reduce system demand and save system capacity. The benefit is an efficient system, increasing plant capacity and a big save on financial resources.

\section{REFERENCES}

[1] M. Gown and L. Baine, "Energy Saving Lighting Controllers,” Electrical Installation International, Vol. 3, No. 9, 1999, p. 14.

[2] Department of Energy and Power Development, "Zimbabwe Energy Policy,” 2013, p. 49

[3] Norweigian Institute of Technology, "Economic \& Financial Analysis of Energy Systems,” 1998, p. 122.

[4] PG \& E Tool Lending Library, "California Companies in Measuring Energy Consumption,” 2013. http://www.dentinstruments.com/case-study-library-energ y-cost-savings.html

[5] W. Mungwena "Cogeneration in Zimbabwe Sugar Industries,” JESA, Vol. 23, No. 1, 2012, pp. 67-71.

[6] A. S. Pabla, "Efficient Energy Use in Motors," 1996, pp. 11-17. 